\title{
A Didática Reconstrutivista da História: uma proposta teórica e metodológica para o Ensino de História
} The Reconstructivist Didactics of History: a theoretical and methodological proposal for the Teaching of History

Max Lanio Martins Pina*

Maria da Conceição Silva**

\section{Resenha de: Schmidt, Maria Auxiliadora Moreira dos Santos.}

Didática reconstrutivista da história.

Curitiba: CRV, 2020. 174p.

O livro Didática Reconstrutivista da História da professora e historiadora Maria Auxiliadora Moreira dos Santos Schmidt, publicado em 2020 pela Editora CRV, sediada em Curitiba, é o que existe de mais recente como reflexão teórica e metodológica para o campo da Didática da História no país. A autora percorre o caminho realizado pela influência do pensamento intelectual alemão, da mesma maneira que ressalta o influxo das reflexões realizadas no contexto da linha de investigação da Educação Histórica ibérica (portuguesa) e anglo-saxônica, da qual faz parte, sendo a principal referência dessa área em solo brasileiro.

Maria Auxiliadora Schmidt, carinhosamente conhecida como "Dolinha" por seus pares, possui uma longa trajetória na educação brasileira, que começou no final dos anos de 1970. Foi professora da educação básica por vários anos na cidade de Curitiba, apropriadamente do Ensino Fundamental II, o que a possibilitou conhecer a realidade do ensino na escola pública no Brasil. Como docente da Universidade Federal do Paraná (UFPR), atuou na formação de professores e pesquisadores das áreas de História e Educação e colaborou, e até o momento colabora, com instituições acadêmicas brasileiras, europeias e ibero-americanas. Atualmente, a pesquisadora é professora titular aposentada

\footnotetext{
* Universidade Estadual de Goiás (UEG), Porangatu, GO, Brasil. maxilanio@yahoo.com.br

** Universidade Federal de Goiás (UFG), Goiânia, GO, Brasil. mariacsgo@ufg.br
} 
e está vinculada ao Programa de Pós-Graduação em Educação (PPGE) e ao Laboratório de Pesquisa em Educação Histórica (LAPEDUH) da UFPR, tendo sido a fundadora deste.

O LAPEDUH transformou-se numa referência para o Ensino de História, e pode ser considerado o espaço que possibilita a professora Maria Auxiliadora Schmidt realizar suas pesquisas, bem como efetuar a orientação de alunos de mestrado, doutorado e pós-doutorado, com vistas ao desenvolvimento de investigações no campo da Educação Histórica, tendo como princípio o paradigma da aprendizagem histórica. A historiadora é presidente da Associação Iberoamericana de Pesquisadores da Educação Histórica (AIPEDH), mantendo vínculos com uma de rede de pesquisadores e intelectuais na Europa (Alemanha, Inglaterra, Portugal, Espanha e Itália), na América do Norte (Estados Unidos, Canadá e México) e na América do Sul (Chile, Colômbia e Argentina). A pesquisadora também é bolsista de produtividade em pesquisa $1 \mathrm{~B}$ do Conselho Nacional de Pesquisa (CNPq), e, ainda, dispõe de vários artigos, livros e capítulos de livros publicados ao longo de sua carreira.

O livro Didática Reconstrutivista da História está divido em quatro capítulos, que possuem a finalidade de apresentar a trajetória intelectual da pesquisadora, assim como explicitar sua construção teórico-metodológica para o Ensino de História, que poderia ser chamada de novo paradigma para a aula de história. Sua perspectiva está focada na aprendizagem fundamentada na epistemologia da ciência de referência. A obra é produto de revisão da tese defendida pela autora em 2019, para progressão na sua carreira funcional no magistério superior como Professora Titular na UFPR.

A apresentação do livro ficou sob responsabilidade da pesquisadora Marlene Cainelli, professora da Universidade Estadual de Londrina (UEL), que procurou, no prefácio, responder qual a motivação, o sentido e as carências de orientação que conduziram a historiadora Maria Auxiliadora Schimdt a escrever a obra. Além dessas questões, Marlene Cainelli enfatiza que o exemplar é uma possibilidade de leitura inovadora sobre a natureza didática do conhecimento histórico, tendo em vista que recupera a proposta de um ensino de História denso, estruturado e fundamentado, principalmente, na ciência histórica.

A introdução da obra visa responder o porquê de uma Didática Reconstrutivista da História, que segundo a autora foi formulado por meio do debate existente na Filosofia da História, com vista à sua relação com a aprendizagem 
do passado, fugindo assim, das discussões do campo da ciência da Educação. Partindo do consenso de que a Didática da História é a ciência da aprendizagem histórica, a pesquisadora conceitua a Didática Reconstrutivista da História como uma adesão ao fato de que a aprendizagem e a cognição histórica precisam ser referenciadas na História, na intenção de estabelecer metodologias que privilegiem, durante a aula de História, a relação passado, presente e futuro como uma reconstrução que possibilite novas narrativas históricas.

O capítulo inicial apresenta a visão da autora sobre o conceito transposição didática do francês Yves Chevellard e como ele esteve presente no Ensino de História em suas variações e adaptações, que foram efetuadas por intelectuais no decorrer do século XX. Ainda nessa primeira parte da obra, a pesquisadora analisa o pensamento de intelectuais brasileiros que, desde o início do século $\mathrm{XX}$, trouxeram contribuições metodológicas para o estabelecimento do Ensino de História, a começar pelo intelectual Jonathas Serrano e sua proposta de 1917, finalizando com a análise dos Parâmetros Curriculares Nacionais (PCNs) de 1998, editados pelo Ministério da Educação (MEC). Em oposição à ideia da transposição didática, Maria Auxiliadora Schmidt apresenta o conceito de cognição histórica situada. Nesse sentido, a autora intenciona demonstrar, por meio do desenvolvimento das pesquisas em Educação Histórica e sua relação com a Didática da História alemã, que a aprendizagem histórica está relacionada à adoção de uma metodologia de ensino vinculada à ciência de referência, na mobilização da consciência histórica e, sobretudo, nas influências da História pública, que necessita ser levada em consideração no espaço escolar.

O capítulo seguinte discute a aprendizagem como fundamento da Didática Reconstrutivista da História. A autora inicia questionando por que se deve aprender História, o que para ela não é uma resposta simples, dado que, conforme os intelectuais que são apropriados, as respostas serão múltiplas. Todavia, encarar esse fundamento coloca a questão elementar que é a reconstrução do passado na aula de História como ponto de partida, o que, de acordo com a pesquisadora, permite a adesão ao pressuposto da narrativa como forma e função da aprendizagem histórica. A reconstrução do passado é necessária à medida em que as carências de orientação individuais ou sociais se modificam e são transformadas em outras carências. Nesse caso, o passado precisa ser novamente interpretado e reinterpretado pela consciência histórica, para permitir a orientação temporal dos sujeitos. Por isso, existe a necessi- 
dade do aluno (criança e jovem) aprender a pensar historicamente. Isso não significa transformá-lo num pequeno historiador, mas permitir que alcance as mesmas categorias mentais que os historiadores atingem quando estão analisando o passado e produzindo historiografia. Sendo assim, a pesquisadora sugere que a aprendizagem histórica precisa começar e terminar na consciência histórica. Para ela, o conceito de literacia histórica, de autoria do historiador inglês Peter Lee, consegue responder bem, porque é através do aprender a pensar historicamente que as crianças e jovens absorvem as categorias da História e do sentido histórico.

No capítulo três, a historiadora apresenta como a formação do pensamento histórico é a finalidade de uma Didática Reconstrutivista da História. Ela acredita que a formação do pensamento histórico é um desafio para a aprendizagem histórica, visto que é necessário ocorrer por meio da apropriação da produção histórica de sentido. Isso ocorre quando a experiência do tempo é alcançada pela dimensão da interpretação do tempo. O indivíduo tem que saber lidar com a história individual e com a história coletiva, organizando sua vida dentro da estrutura do tempo, com a finalidade de orientar intencionalmente seu futuro. Nesse contexto, Maria Auxiliadora Schmidt defende que a aprendizagem histórica precisa acontecer a partir das carências de orientação dos indivíduos envolvidos nos processos de ensino e aprendizagem. Seria preciso, então, ocorrer uma mudança nos currículos de História no Brasil, visto que eles estão fechados dentro de uma visão quadripartite eurocêntrica do tempo e também estão a serviço dos interesses do Estado.

Outro ponto importante do capítulo três é o momento que, dialogando com os autores Peter Seixas, Carla Peck, Peter Lee e Jörn Rüsen, a autora propõe uma matriz para as competências do pensamento histórico. Essa matriz tem como objetivo principal servir de referência para o modo como opera a aprendizagem histórica, tendo em vista atingir uma das metas da Didática da História, que é construir a competência de atribuição de sentido pela narrativa histórica. As categorias apresentadas pela pesquisadora são as seguintes: argumentação, significância, evidência, mudança, empatia, interpretação, explicação, motivação, orientação e experiência (percepção). Todas essas categorias estão pensadas e fundamentadas no contexto da Filosofia da História germânica, ibérica e anglo-saxã. Para finalizar o capítulo, a autora ainda debate dois influentes pensadores, Jörn Rüsen e Paulo Freire, para demonstrar o hu- 
manismo como fundamento da Didática Reconstrutivista da História, indicando a necessidade de pautar o Ensino de História dentro dessa perspectiva, para contribuir com as formas básicas do processo de formação para a humanização.

No quarto e último capítulo, Maria Auxiliadora Schmidt apresenta sua proposta intitulada de Aula Histórica. Nela, demanda apresentar uma teoria e uma metodologia que estão pautadas na ideia de uma Didática Reconstrutivista da História, que foi amadurecida por meio de diálogo e reflexões com intelectuais europeus e canadenses. Há que ressaltar que o primeiro modelo tipológico de Matriz da Aula Histórica foi utilizado no ano de 2016, como referência das Diretrizes Curriculares para o Ensino de História da Rede Municipal de Ensino de Curitiba, no estado do Paraná. Inspirada na Aula Oficina da professora e pesquisadora portuguesa Isabel Barca, a autora buscou subsídios na Matriz da Didática da Educação Histórica de Peter Seixas, na Matriz da Didática da Educação Histórica de Stéphane Lévesque, na Matriz Disciplinar da História e também na Matriz da Didática da História de Jörn Rüsen, para elaborar tanto a primeira, quanto a segunda Matriz da Aula Histórica.

Em sua última matriz, Maria Auxiliadora Schmidt estrutura a aula de História na mesma perspectiva de Jörn Rüsen, quando aborda a relação tipológica entre a vida prática (embaixo) e a ciência (em cima) numa circunferência em que existem essas duas divisões. A novidade acrescida pela autora é o fato da vida prática estar subsidiada em categorias entre a Cultura Infantil e Juvenil e a Cultura da Escola. É a partir dessas categorias que são entrelaçados os conteúdos Memória, Patrimônio e História Controversa, que necessitam ser levados em conta em suas formas horizontal e vertical durante a aula de História. Percebe-se que a História Controversa ocupa um ponto importante nas reflexões da autora, que, citando o historiador e didaticista alemão Bodo von Borries, espera que os historiadores-professores possam continuar enfrentando todos os temas difíceis, controversos e desconfortáveis da História.

Seguindo as introduções realizadas pela pesquisadora na sua segunda matriz, observa-se também que, no campo superior da circunferência, precisamente onde está representada a ciência, encontram-se articuladas a Cultura Histórica e a Cultura Escolar. É nesse campo que a metódica da Ciência Histórica necessita ser considerada, para que ocorra a reconstrução do passado na Aula Histórica. No centro da Matriz proposta para uma Didática Reconstrutivista da História encontra-se a categoria sentido, em específico a atribuição 
de sentido pela narrativa histórica. Neste ponto, percebe-se que a proposta articulada pela pesquisadora leva em consideração que historiadores-professores necessitam articular todos os elementos categoriais da Matriz, não para realizar uma transposição didática dos conteúdos acadêmicos de História, mas para atuarem a partir da reconstrução do passado pela perspectiva do método histórico.

Para finalizar seu último capítulo, a historiadora discute um tema polêmico, porém necessário, a ser enfrentado, posto que dicotomizou a práxis na História, colocando-se de um lado o historiador (aquele que pesquisa) e do outro, o professor (aquele que ensina). Por meio de um processo histórico longo que estabeleceu essa separação, a situação precisa ser superada, tendo em vista o avanço da pedagogia das competências no Ensino de História, que elimina a atribuição de sentido do pensamento histórico na vida prática como orientação temporal dos sujeitos no tempo presente. Assim, a pesquisadora afirma sem titubear, que o historiador que pesquisa é também um professor, e o professor que ensina é também um historiador, encontrando dessa maneira o elo que justifica sua Didática Reconstrutivista da História.

O livro Didática Reconstrutivista da História é, sem dúvida, um marco conceitual que visa à construção de uma teoria e uma metodologia para o Ensino de História no Brasil. Assegura-se que a obra é uma robusta reflexão intelectual, construída ao longo de anos de experiência, com a finalidade de propor, a partir dos reais problemas que são enfrentados por milhares de professores no chão da sala de aula, uma teoria do ensino e da aprendizagem histórica fundamentada na ciência de referência, valorizando principalmente a função do historiador-professor-pesquisador.

Resenha recebida em 31 de julho de 2020. Aprovada em 9 de setembro de 2020. 